\title{
Testes comportamentais em roedores para o estudo do transtorno do espectro autista
}

\author{
Behavioral tests in rodents for the study of autistic spectrum disorder
}

Recebido em: 03/11/2020 Aceito em: $28 / 01 / 2021$
Caroline de Oliveira VIANA; Maria Fernanda Mendes FELISMINO; Luana Letícia Alves DUTRA; Tatiana Paschoalette Rodrigues BACHUR;

Gislei Frota ARAGÃo

${ }^{1}$ Centro Universitário Unichristus. Rua João Adolfo Gurgel, CEP 60.190-180 133. Cocó. Brasil.

E-mail: tatiana.bachur@uece.br

\section{ABSTRACT}

Autistic spectrum disorder (ASD) is a neurodevelopmental disorder in which its behavioral changes and the developmental stages of these changes can be investigated using animal models of ASD and by conducting behavioral tests to assess the changes. This research aimed to carry out a survey in the literature on the animal behavioral models used to study the autistic spectrum disorder and the correlation of these models with human behavior in ASD, through is a narrative review conducted based on the search for scientific articles on the study theme from June to September 2019, using the Medline, Web of Science and Clinical Key databases. In the TEA study, behavioral tests are performed based on the clinical characteristics and manifestations of the disorder. These tests are performed on animals and used to assess the potential inducer of substances for the development of ASD and in studies conducted to evaluate potential drugs or non-pharmacological therapies for the treatment of the disorder. The most commonly used tests are: open field test, glass ball burial test (marble burying test), social interaction test, repetitive self-cleaning behavior test, elevated plus maze test, olfactory habituation test, social odors, and light-dark test. When surveying the behavioral tests used in experimental research on animals on the autism spectrum disorder, the importance of these in vivo models of TEA study is reiterated, enabling a greater understanding of behavioral changes and, consequently, a better understanding of this disorder.

Keywords: Autism spectrum disorder; Behavior and behavior mechanisms; Behavioral symptoms; Behavioral disciplines and activities; Animal models.

\section{RESUMO}

O transtorno do espectro autista (TEA) é um transtorno do neurodesenvolvimento cujas alterações comportamentais podem ser investigadas por meio de modelos animais de TEA e pela realização de testes comportamentais para avaliação das alterações. O objetivo deste trabalho foi realizar uma pesquisa bibliográfica sobre os modelos comportamentais animais que têm sido utilizados para o estudo do TEA e a correlação desses modelos com o comportamento humano no TEA. Para esta pesquisa bibliográfica, foi conduzida 
uma busca nas bases de dados Medline, Web of Science e Clinical Key, no período de junho a setembro de 2019, por artigos científicos na temática de estudo, sendo selecionados artigos publicados entre os anos de 2006 e 2019. No estudo experimental do TEA, são conduzidos testes comportamentais em animais considerando as características clínicas e manifestações do transtorno. Estes modelos experimentais são utilizados para a avaliação do potencial indutor de substâncias para o desenvolvimento do TEA, como para a avaliação de potenciais fármacos ou terapias não farmacológicas para o tratamento do transtorno. Os testes mais comumente utilizados são: teste de campo aberto, teste de enterramento de esferas de vidro, teste de interação social, teste do comportamento repetitivo de autolimpeza, teste do labirinto em cruz elevado, teste de habituação olfativa e odores sociais e teste claro-escuro. Reitera-se a importância desses testes em modelos in vivo de estudo do TEA, possibilitando uma maior compreensão das alterações comportamentais e um melhor entendimento desse transtorno.

Palavras-chave: transtorno do espectro autista; comportamento e mecanismos comportamentais; sintomas comportamentais; disciplinas e atividades comportamentais; modelos animais.

\section{INTRODUÇÃO}

O transtorno do espectro autista (TEA), descrito pela primeira vez em 1943 por Leo Kanner, é um transtorno do neurodesenvolvimento, caracterizado por déficits de comunicação social, interesses restritos, presença de comportamentos e atividades estereotipadas e interação social mútua atípica (1).

A diminuição do interesse em socializar configura um dos déficits mais frequentes em indivíduos com TEA (2). Outras manifestações que podem ocorrer incluem deficiência intelectual, crises epilépticas, comportamentos agressivos impulsivos, comportamentos de autoagressão, sensibilidade exacerbada à estimulação sensorial e às diversas formas de ansiedade (2-4). Esses sintomas se mostram relevantes desde o início da infância, podendo limitar ou afetar o desenvolvimento da criança, levar à incapacidade social, acadêmica e ocupacional, além de acarretar impactos emocionais e econômicos na família e também custos para a sociedade e o sistema de saúde $(4,5)$.

O TEA tem sido descrito como um dos transtornos pediátricos mais prevalentes que acometem o desenvolvimento neuropsicomotor (6). É uma condição que pode ser observada em ambos os gêneros, sendo mais prevalente em indivíduos do sexo masculino. Estimativas mostram que, para cada menina diagnosticada com TEA, aproximadamente 3,5 a 4,0 meninos são identificados. Algu- mas teorias procuram explicar esse dado, porém, até o momento, nenhuma foi conclusiva (5).

O TEA possui etiologia desconhecida complexa e multifatorial. A literatura aponta alguns fatores relacionados ao desenvolvimento do TEA, como condições ambientais, neurobiológicas, neuroanatômicas, metabólicas, imunológicas, uma grande variedade de fatores genéticos e a exposição a diversas substâncias $(3,7,8)$. Além disso, outro fator passou a ser associado a um fenótipo mais grave de TEA, que é o estresse materno pré-natal, principalmente sob grande número de exposições estressantes, em que foi demonstrado que, em modelos de roedores, atrasa-se o desenvolvimento GABAérgico, afetando a preferência social e aumentando o comportamento semelhante à ansiedade na prole $(9,10)$.

As alterações comportamentais em um indivíduo, bem como os estágios de desenvolvimento dessas alterações, podem ser investigadas por meio de modelos animais de TEA e da realização de testes comportamentais para avaliação das alterações $(9,11)$.

Neste contexto, o objetivo do presente trabalho foi realizar uma pesquisa bibliográfica buscando responder a seguinte pergunta: quais os modelos comportamentais animais que têm sido utilizados para o estudo do transtorno do espectro autista? Tem-se como hipótese que os testes realizados em animais para estudo do TEA devem ter estreita correlação com o comportamento humano no transtorno. 


\section{MÉTODO}

O intuito desta revisão foi mapear o conhecimento atual sobre os testes comportamentais utilizados em ensaios in vivo para o estudo do TEA por meio da análise de dados secundários. Para tal, foi conduzida uma pesquisa bibliográfica, no período de junho a setembro de 2019, para a seleção de artigos científicos publicados nas bases de dados Medline, Web of Science e Clinical Key. Foram utilizados os seguintes descritores $\mathrm{MeSH}$ e suas combinações: "Autistic Disorder", "Austism Spectrum Disorder", "Models, Animal"; "Laboratory Animal Model"; "Experimental Animal Model". O critério de inclusão consistiu em artigos originais, publicados entre os anos de 2006 e 2019, no idioma inglês, cujos estudos utilizassem testes comportamentais para modelos in vivo no estudo do TEA. Foram excluídos estudos cuja espécie animal não era roedores, artigos de revisão de literatura, bem como aqueles indisponíveis na íntegra. A relevância dos artigos foi determinada considerando a clareza no delineamento metodológico da pesquisa, além de considerar o grau de significância dos resultados apresentados.

\section{RESULTADOS E DISCUSSÃO}

As buscas iniciais por meio dos descritores e suas combinações resultaram em 910 artigos; outros 10 artigos foram obtidos de outras fontes. Após a triagem pelo título resultaram 128 artigos, sendo removidas 9 duplicatas. Após a remoção das duplicatas, foram lidos os resumos dos 119 artigos restantes, dos quais 39 não se enquadraram nos critérios de inclusão, sendo retirados nesta etapa, restando 80 artigos para leitura de texto completo. Foi realizada a leitura na íntegra dos 80 artigos restantes, sendo excluídos 48 artigos por não utilizarem testes comportamentais, resultando em 32 artigos, conforme demonstrado no diagrama de fluxo (Figura 1). As metodologias empregadas pelos autores referenciados nesta revisão estão sumarizadas no Quadro 1

O estudo experimental do TEA tem como base a realização de testes comportamentais em animais levando em consideração as características clíni- cas e manifestações deste transtorno. Esses testes podem ser utilizados para a avaliação do potencial indutor de substâncias para desenvolvimento do TEA, bem como para a avaliação de potenciais fármacos ou terapias não farmacológicas para o tratamento do transtorno, sendo roedores (ratos e camundongos) os animais mais comumente utilizados $(6,12)$.

$\mathrm{Na}$ literatura analisada, foram descritos os seguintes testes: teste do campo aberto, teste de enterramento de esferas de vidro, teste de interação social, teste do comportamento repetitivo de autolimpeza, teste do labirinto em cruz elevado, teste de habituação olfativa e odores sociais e teste claro-escuro.

Teste do campo aberto. Um dos testes mais utilizados e reconhecidos para avaliação do comportamento animal no TEA é o teste do campo aberto (TCA) o qual foi citado em 13 dos 32 artigos utilizados (40,6\%). Trata-se de um teste para avaliação do comportamento exploratório e locomoção dos animais estudados $(8,10,13)$.

O TCA, desenvolvido por Hall em 1934 (14), é realizado em um aparato que consiste em uma arena quadrangular em acrílico transparente, medindo 45 $\mathrm{cm} \times 45 \mathrm{~cm}$, cercada por paredes de, aproximadamente, $22 \mathrm{~cm}$ de altura, de modo que o animal em teste não consiga fugir (10). Para facilitar a quantificação da atividade locomotora dos animais, o piso do campo aberto é dividido em nove quadrados idênticos, por entre os quais o animal irá circular, e o número de cruzamentos realizados pelos animais entre os quadrados será quantificado $(14,15)$.

O tempo total empregado no teste depende do objetivo da pesquisa e do avaliador. A literatura consultada apontou duração dos experimentos variando de 5 a 90 minutos $(6,10,15)$. No entanto, o protocolo mais citado utilizou o tempo total de 15 minutos, sendo 5 minutos de habituação e 10 minutos de teste, realizados em um único dia (13).

A espécie de roedor a ser utilizada também pode variar de acordo com os objetivos do trabalho, podendo ser utilizados ratos ou camundongos de ambos os sexos. No entanto, a literatura avaliada revelou que os animais machos têm sido os mais utilizados neste teste comportamental aplicado nas pesquisas sobre TEA. 
Figura 1. Metodologia utilizada para a seleção de artigos sobre transtorno do espectro autista (TEA).

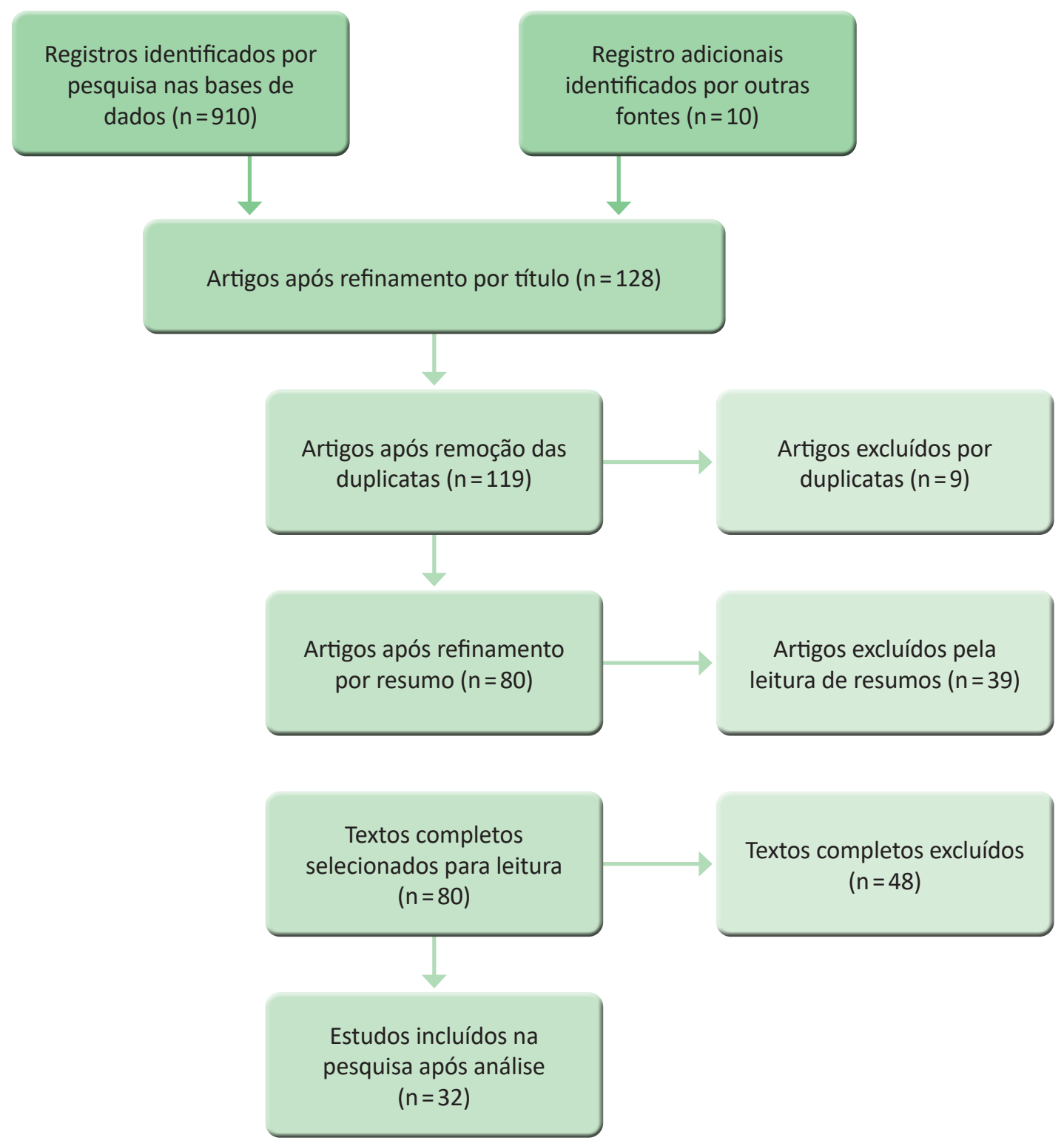

Considerando o tempo de 15 minutos, o mais comumente descrito nos estudos analisados nesta revisão, a descrição do teste consiste em, inicialmente, colocar o animal em teste no centro do aparato e deixá-lo explorar toda a área durante 5 minutos para habituação; nesse tempo, não será contabilizada nenhuma movimentação. No segundo momento do teste, que compreende os 10 minutos seguintes (13), o animal é observado e são analisados diferentes parâmetros, tais como a movimentação no campo aberto, o número de cruzamentos entre os quadrados (crossing), a distância total percorrida, o comportamento exploratório, o tempo gasto no centro do aparato, a quantidade de idas ao centro do campo aberto, número de quadrados percorridos, a quantidade de defecação, número de self grooming e a quantidade de vezes em que se apoiam somente em duas patas (rearing) $(8,14)$.

As observações podem ser verificadas e contabilizadas de forma manual por um avaliador ou mediante software de rastreamento de vídeo automatizado como o AnyMaze (Stoelting Any Maze 
Software, Wood Dale, IL) (10), e o NIH IMAGE OF (O’Hara \& Co., Tóquio, Japão) (13).

$A$ atividade motora, associada à defecação no campo aberto, gera informações, principalmente, sobre o estado emocional do animal em teste $(9,14)$. A associação entre alta taxa de defecação e baixa atividade locomotora no animal-teste em comparação a animais-controle são indícios de ansiedade $(9,14)$. O tempo gasto no centro do aparelho sem atos exploratórios também foi apontado como indicador de ansiedade. $\mathrm{O}$ aumento no número de autolimpezas foi considerado um indicativo de movimentos estereotipados, característica que é encontrada em indivíduos com TEA, os quais, comumente, realizam movimentos repetitivos $(6,8,10)$.

As estereotipias em crianças com TEA podem ser explicadas por algumas hipóteses. Uma dessas teorias sugere que ocorrem limitações de comunicação entre as regiões frontal e posterior do cérebro, afetando a comunicação entre estas áreas, podendo gerar os comportamentos repetitivos. Outra hipótese é referente à saída involuntária de um impulso motor desregulado, envolvendo os gânglios da base e as vias dopaminérgicas basais. Outra hipótese bastante discutida é que as estereotipias ocorrem de forma compensatória quando os indivíduos recebem um excessivo estímulo externo (16).

Após a realização do teste, o aparato deve ser limpo com álcool e deixado sem uso o tempo suficiente para que ocorra a evaporação do etanol e a dissipação do odor antes da utilização dessa câmara por outro animal $(8,10)$.

Teste de enterramento de esferas de vidro. $\mathrm{O}$ teste de enterramento de esferas de vidro (marble buring test) foi citado em 10 dos 32 artigos utilizados $(31,2 \%)$. Esse teste é realizado em uma caixa grande, contendo uma "cama" de maravalha com profundidade de $2 \mathrm{~cm}$, sobre a qual são colocadas 20 esferas de vidro ("bolas de gude") de forma organizada e equidistantes $(9,17,18)$. Esse teste se vale da habilidade para cavar que os roedores apresentam em ambientes próprios como tocas e túneis $(9,19)$.

O benefício de utilizar esse teste é, principalmente, a sua facilidade de execução, também podendo ser citadas a precisão de pontuação do comportamento avaliado e a exibição espontânea desses comportamentos em roedores. Outra van- tagem é a mínima necessidade de habituação dos animais ao teste, já que esse é realizado em gaiolas (caixas) nos padrões normalmente utilizadas pelos animais, além de dispensar a restrição alimentar ou de água para os animais em teste $(12,17)$.

$\mathrm{O}$ animal é colocado no centro da caixa de teste por um tempo que pode ser de 10 a 45 minutos e, ao final desse tempo, é removido da caixa e, então, feita a análise (19). O comportamento repetitivo do animal é avaliado a partir do número de esferas enterradas em 50 a $100 \%$ do seu volume, sinalizando o grau de estereotipia por meio da demonstração do comportamento repetitivo, compulsivo e persistente em modelos animais $(9,18,19)$. Assim, este teste é empregado para verificar a ansiedade e comportamentos repetitivos semelhantes comuns no TEA (9). Animais experimentalmente induzidos ao TEA enterram e deslocam mais esferas do que os animais não induzidos por conta da execução de movimentos repetitivos de escavação, caracterizando um padrão de estereotipia também observado em crianças com TEA, e por conta disso, o teste de enterramento de esferas de vidro é bastante utilizado em modelos animais de estudo do TEA $(9,12,17)$.

Teste de interação social. O teste de interação social ou teste de três câmaras foi citado em 13 dos 32 artigos utilizados (40,6\%). Esse teste é bastante empregado para analisar o comportamento social, a busca de novidades sociais, o reconhecimento de pistas sociais e a interação social de animais em estudos sobre o TEA $(8,10)$.

$\mathrm{O}$ aparato do teste consiste em um retângulo de acrílico dividido em três câmaras iguais, no qual o animal tem acesso às três câmaras por meio de aberturas presentes nas divisórias entre as câmaras $(6,8)$.

A metodologia do teste de interação social consiste em sessões de habituação, sociabilidade e novidade social (10). Para a habituação, o animal é colocado no compartimento central do aparato, podendo explorar livremente as outras câmaras por período de 5 a 10 minutos (8). Na sessão de sociabilidade e novidade social, o animal é colocado novamente ao centro; porém, é acrescentado um animal estranho sob uma grade em uma das câmaras laterais (câmara teste) e uma grade vazia na outra câmara lateral (câmara oposta), sendo permitido ao 
animal percorrer e explorar todas as câmaras por um período de 8 minutos $(4,6,10)$.

Nessa etapa, preferência social e interação são definidas como permanecer significativamente mais tempo com o animal estranho (na câmara teste) do que na câmara oposta (10). As interações sociais avaliadas neste teste consistem em cheirar focinho a focinho, inspeção anogenital, exploração de flanco e comportamento de seguir (4). A quantidade e a duração da interação são pontuadas, sendo também calculado o número total de entradas na câmara teste e o tempo de interação social recíproca $(4,6,8,10)$. Os testes são filmados e depois analisados estatisticamente $(4,10)$.

Uma das características mais significativas do TEA consiste no prejuízo de interação social, que pode ser evidenciado através da dificuldade em participar de atividades de grupo, tendência ao isolamento, desapego afetivo e falta de empatia social. Esta interação social pode estar prejudicada por déficits sensoriais, alterações de linguagem e dificuldade de comunicação (4). Animais experimentalmente induzidos ao TEA têm uma tendência a apresentar número e tempo significativamente menores de interação com um animal desconhecido, apresentação comportamental semelhante à encontrada em indivíduos com TEA $(6,8)$.

Teste do comportamento repetitivo de autolimpeza. $\mathrm{O}$ teste do comportamento repetitivo de autolimpeza foi citado em 10 dos 32 artigos utilizados (31,2\%). O comportamento de autolimpeza é um comportamento natural e articulado principalmente pelo estado de ansiedade do animal (4). Sua avaliação tem como objetivo observar a presença de estereotipias e suas repetitividades (20), que são bastante frequentes em animais modelos de estudo de TEA $(4,9)$. Esse comportamento compõe-se de movimentos em que o animal lambe as patas anteriores, a barriga e o dorso em uma progressão estereotipada (9).

Na avaliação do comportamento de autolimpeza, o roedor é colocado em uma gaiola padrão (9) - vazia para evitar o comportamento de escavação - por ser competitivo com a estereotipia do comportamento de autolimpeza (21). Os 10 primeiros minutos são de habituação sem que seja marcada nenhuma pontuação (20); nos minutos seguintes, que variam de 5 a 20 dependendo do protocolo e do avaliador, são pontuados a quantidade de vezes que o animal faz o movimento e o tempo de duração do movimento (9). Os animais típicos (não induzidos ao TEA) normalmente friccionam os pelos com as patas anteriores com tempo de duração de segundos ou até minutos (4). Quando a autolimpeza é realizada por um tempo superior ao tempo dos animais típicos, este é considerado um comportamento repetitivo (9).

Animais com características do TEA apresentam maior taxa de autolimpeza quando comparados com animais neurotípicos, manifestando um aumento na duração média dos episódios de autolimpeza, assim como na frequência desses eventos $(9,22)$. A atividade de autolimpeza tem sido empregada como um índice de comportamento repetitivo relevante para os estudos pré-clínicos do TEA, pois demonstra que os animais induzidos ao TEA manifestam comportamento estereotipado semelhante ao de indivíduos humanos com o transtorno $(4,9,21,22)$.

Teste do labirinto em cruz elevado. O teste do labirinto em cruz elevado (LCE) foi citado em 9 dos 32 artigos utilizados $(28,1 \%)$. Esse teste foi descrito, inicialmente, por Pellow e File (1986) (23), sendo um teste bastante utilizado em modelos animais de TEA, pois seus achados se relacionam com a ansiedade $(18,24)$, explorando a tendência inata de medo por espaços abertos dos roedores, traduzido pelo afastamento dos animais dos braços abertos do labirinto $(9,25,26)$. Apesar de a ansiedade não ser a principal manifestação clínica do TEA, é considerada um problema recorrente nesses indivíduos (27).

O labirinto em cruz elevado fica a $30 \mathrm{~cm}$ de altura do solo e é composto por quatro braços $(30 \mathrm{~cm}$ $\times 6 \mathrm{~cm} \times 15 \mathrm{~cm})(9)$, sendo dois fechados e dois abertos, separados por um centro, que é o marco inicial do teste $(23,28)$. Uma borda de $0,5 \mathrm{~cm}$ de altura cerca as bordas dos braços abertos (18), e paredes de $40 \mathrm{~cm}$ de altura cercam os braços fechados (24).

O animal é, inicialmente, colocado no centro do labirinto com o rosto direcionado para um dos braços abertos, sendo-lhe permitida a exploração do labirinto livremente $(9,27)$. A duração do teste 
pode variar de 5 a 15 minutos de acordo com a literatura $(9,24-28)$.

A avaliação é feita de acordo com o tempo gasto nos braços abertos, o tempo gasto nos braços fechados, a quantidade de vezes que ele entra nos braços abertos, a quantidade de vezes que entra nos braços fechados, bem como a parada no centro do labirinto $(24,26,28)$. Para quantificar o tempo gasto em cada parte do labirinto, é necessária a utilização de três cronômetros: um para contar o tempo total de teste, um para contar o tempo nos braços fechados e o terceiro para contar a quantidade de tempo em que o animal-teste fica nos braços abertos $(24,25)$.

Em modelos animais de TEA, é observada uma menor utilização e entradas nos braços abertos que são consideradas luminosas, aversivas e inseguras em relação aos braços fechados considerados escuros e protegidos, o que pode ser justificado pelo sentimento de afastamento e estranheza após a exposição a um novo ambiente, também demonstrando sinais de ansiedade e medo, manifestações presentes no TEA $(9,26)$.

A ansiedade pode gerar uma série de alterações comportamentais encontradas no TEA, tais como comportamentos repetitivos, rituais, déficits sociais, irritabilidade e medo. Essa ansiedade pode ser determinada por dois fatores: 1) o grau da ameaça do evento - indivíduos no espectro apresentam dificuldade em reconhecer o nível de ameaça sofrido, com isso podem responder de forma exacerbada a um estímulo, transformando pequenos eventos em situações altamente ameaçadoras; o próprio déficit sensorial destes indivíduos pode culminar em uma reação intensificada; 2) o controle que o indivíduo tem sobre um determinado fator estressor - indivíduos com TEA normalmente sentem-se impotentes em administrar os eventos que os rodeiam, inclusive aqueles potencialmente estressores, gerando uma alta ansiedade e sentimento de insegurança e medo (29).

Teste de habituação olfativa e odores sociais. O teste de habituação olfativa e odores sociais foi citado em 7 dos 32 artigos utilizados (21,8\%). As interações sociais dependem, fortemente, de informações olfativas. A comunicação em roedores depende, principalmente, da olfação $(20,30)$.
A avaliação da comunicação olfativa é feita por meio de pistas olfativas não sociais e sociais $(6,12,18,30)$. O animal é colocado em uma gaiola plástica limpa e habituado, geralmente, por um período de 10 minutos com um algodão sem nenhum odor (30). Após esse período, o roedor recebe odores sociais e não sociais por cerca de 3 minutos cada um (20). Odores não sociais são selecionados por ser uma novidade para o roedor, podendo ser imitações de extratos de banana, amêndoa e baunilha. Já os odores sociais são selecionados por familiaridade, podendo ser utilizados maravalha suja de suas gaiolas ou algodão sujo com urina de outros machos ou fêmeas, odores familiares para o animal $(12,18,30)$.

No decorrer do período de apresentação das dicas olfativas, o comportamento do roedor é avaliado de acordo com o número de farejadas e a duração que o roedor fareja, podendo ser pontuado manualmente ou por meio de vídeo e software $(6,12,18,30)$. Dicas olfativas são um componente importante da investigação social de roedores. Odores não sociais, geralmente, só provocam um nível modesto de resposta de cheirar. Já os odores sociais são considerados mais atraentes pelos roedores e podem provocar uma resposta inicial mais forte ao cheirar $(12,20)$.

Teste claro-escuro. O teste de exploração claro-escuro foi citado em 6 dos 32 artigos utilizados $(18,7 \%)$. Esse teste é aplicado para a avaliação do comportamento de ansiedade $(9,18,31)$, e é realizado em uma caixa grande dividida em dois compartimentos: o compartimento maior, cerca de $2 / 3$ do tamanho total da caixa, é chamado de espaço claro, aberto superiormente e iluminado por uma lâmpada de $100 \mathrm{~W}$ posicionada a $90 \mathrm{~cm}$ acima do aparelho; um pequeno compartimento preto composto por $1 / 3$ do tamanho da caixa que é chamado de espaço escuro e é coberto por uma tampa preta removível; entre os dois compartimentos, existe uma abertura, medindo $7 \mathrm{~cm}$ e posicionada na altura do chão da caixa $(32,33)$. O tamanho total da caixa é, geralmente, de $46 \times 27 \times 30 \mathrm{~cm}(1 \times \mathrm{c} \times$ a), sofrendo algumas alterações de acordo com o tipo de estudo realizado e com seu pesquisador (32). O animal é colocado no centro da câmara iluminada e liberado para explorar entre as câmaras por um período de 10 minutos (9). A partir disso, é contado o tempo 
utilizado no lado escuro da câmara e o número total de transições entre as câmaras do lado claro e escuro, que podem ser pontuados pelo avaliador ou por meio de softwares $(32,34)$.

Uma diminuição na quantidade de tempo gasto no compartimento claro bem como no número de entradas dos animais neste compartimento evidencia um comportamento de ansiedade $(18,32)$. Apesar de roedores terem o instinto de explorar novos ambientes, aqueles que são induzidos ao TEA tendem a demonstrar repulsa ao espaço claro, o que dificulta ou impede o comportamento exploratório desses roedores, o que pode ser explicado pela presença de alto grau de ansiedade nestes animais $(9,32)$.

\section{CONCLUSÃO}

Os testes comportamentais mais comumente utilizados no estudo experimental do transtorno do espectro autista foram teste de campo aberto, teste de enterramento de esferas de vidro, teste de interação social, teste do comportamento repetitivo de autolimpeza, teste do labirinto em cruz elevado, teste de habituação olfativa e odores sociais e teste claro-escuro. Os testes citados na literatura apresentam importante correlação com o comportamento humano no TEA, possibilitando o estudo e a compreensão das alterações comportamentais desse transtorno.

Quadro 1. Resumo das metodologias para estudo experimental do TEA empregadas pelos autores referenciados nesta revisão (publicações entre junho e setembro de 2019)

\begin{tabular}{|c|c|c|c|}
\hline Autor & $\begin{array}{l}\text { Espécie, linhagem e quantidade } \\
\text { de animais }\end{array}$ & Tipo de indução ao TEA & Testes comportamentais \\
\hline $\begin{array}{l}\text { (3) Wagner GC, Reuhl KR, Cheh M, } \\
\text { Mcrae P, Halladay AKA. } 2006 \text {. }\end{array}$ & $\begin{array}{l}\text { Camundongos BALB. } 31 \text { filhotes } \\
\text { expostos a VPA pré-natal ( } n=14 \\
\text { fêmeas e } n=17 \text { machos). Expostos } \\
\text { a VPA pós-natal ( } n=42 \text { machos). }\end{array}$ & $\begin{array}{l}\text { Fase pré-natal: Agente indutor de TEA: VPA } \\
(200 \mathrm{mg} / \mathrm{kg} \text { ); Tempo: E12-17 dias. } \\
\text { Fase pós-natal: Filhotes machos de } 14 \mathrm{~d} \text {; } \\
\text { Indução de TEA: VPA ( } 200 \mathrm{mg} / \mathrm{kg} \text { ou } 400 \\
\mathrm{mg} / \mathrm{kg} \text { ). }\end{array}$ & $\begin{array}{l}\text { Endireitamento de superfície, endireitamento no } \\
\text { ar, Força de preensão do fio suspenso, geotaxia } \\
\text { negativa, feixe de equilíbrio, labirinto aquático, } \\
\text { esquiva passiva, comportamento autolesivo. }\end{array}$ \\
\hline $\begin{array}{l}\text { (5) Bambini-junior V, Rodrigues } \\
\text { L, Behr GA, Moreira JCF, Riesgo R, } \\
\text { Gottfried C. } 2011 .\end{array}$ & $\begin{array}{l}\text { Ratos Wistar. ( } \mathrm{n}=4-6 \text { machos) de } \\
\text { cada ninhada. }\end{array}$ & $\begin{array}{l}\text { Fase pré-natal: Agente indutor de TEA: VPA } \\
(600 \mathrm{mg} / \mathrm{kg}) \text {; Tempo: E12.5 dias. }\end{array}$ & $\begin{array}{l}\text { Teste de sociabilidade de três câmaras, labirinto } \\
\text { em Y, labirinto aquático de Morris. }\end{array}$ \\
\hline (8) Chao OU, Yunger R, Yang Y. 2018. & $\begin{array}{l}\text { Camundongos endogâmicos BTBR } \\
T+\text { Itpr3tf/J (BTBR). ( } n=3-5 \\
\text { machos) por gaiola. }\end{array}$ & $\begin{array}{l}\text { Camundongos machos endogâmicos } \\
\text { BTBR T + Itpr3tf/J (BTBR), um modelo } \\
\text { de camundongo fenotípico com validade } \\
\text { facial para TEA e camundongos machos } \\
\text { C57BL/6J. }\end{array}$ & $\begin{array}{l}\text { Teste de Sociabilidade, Campo Aberto, Teste de } \\
\text { Atenção ao Objeto, Plataforma Elevada Aberta. }\end{array}$ \\
\hline $\begin{array}{l}\text { (9) Cai Y, Wang L, Xiao R, Li X, He X, } \\
\text { Gao J, Xu H, Fan X. } 2017 .\end{array}$ & $\begin{array}{l}\text { Camundongos BTBR } \mathrm{T}+\mathrm{tf} / \mathrm{J} \\
\text { (BTBR). Camundongos machos } \\
\text { foram usados. }\end{array}$ & $\begin{array}{l}\text { Camundongos BTBR } \mathrm{T}+\mathrm{tf} / \mathrm{J} \text { (BTBR) } \\
\text { foram criados a partir de pares adultos e } \\
\text { camundongos } \mathrm{C} 5 \mathrm{BL} / 6 \mathrm{~J} \text { foram fornecidos. }\end{array}$ & $\begin{array}{l}\text { Abordagem social de três câmaras, Interações } \\
\text { sociais recíprocas homem-mulher, Locomoção } \\
\text { em campo aberto, Auto-limpeza, Enterramento } \\
\text { de mármore, Labirinto em cruz elevado, } \\
\text { Transições Lightญdark. }\end{array}$ \\
\hline $\begin{array}{l}\text { (10) Matsui F, Hecht P, Yoshimoto K, } \\
\text { Watanabe Y, Morimoto M, Fritsche K, } \\
\text { Will W, Beversdorf D. } 2018 .\end{array}$ & $\begin{array}{l}\text { Camundongos SERT/S. Apenas } \\
\text { camundongos SERT/S machos } \\
\text { mostraram comprometimento social } \\
\text { e comportamento estereotipado. }\end{array}$ & $\begin{array}{l}\text { Fase pré-natal: Agente indutor de TEA: } \\
\text { estresse com transportador de serotonina } \\
\text { heterozigótica (SERT) KO em camundongos } \\
\text { SERT/S. }\end{array}$ & $\begin{array}{l}\text { Teste de campo aberto, labirinto em cruz } \\
\text { elevado, auto-limpeza, enterramento de } \\
\text { mármore, social de } 3 \text { câmaras. }\end{array}$ \\
\hline $\begin{array}{l}\text { (12) Chang Y, Cole TB, Costa LG. } \\
2018 .\end{array}$ & $\begin{array}{l}\text { Camundongos } \text { C57Bl/6J. ( } \mathrm{n}= \\
2 \text { machos e } \mathrm{n}=2 \text { fêmeas) de } \\
\text { cada ninhada selecionados } \\
\text { aleatoriamente para testes } \\
\text { comportamentais. }\end{array}$ & $\begin{array}{l}\text { As mães grávidas e os filhotes foram } \\
\text { expostos a escapamento de diesel (DE) } \\
\text { (concentração de } 250-300 \mu \mathrm{g} / \mathrm{m} 3 \mathrm{PM} \text { ) } \\
\text { por } 6 \text { h por dia e } 5 \text { dias por semana do dia } \\
\text { embrionário } 0 \text { ao dia pós-natal } 21 \text {. }\end{array}$ & $\begin{array}{l}\text { Teste de campo aberto, teste de preferência } \\
\text { social, interação recíproca, habituação olfativa } \\
\text { a odores sociais, teste de enterrar mármore, } \\
\text { teste de alternância espontânea de labirinto } \\
\text { em T. }\end{array}$ \\
\hline $\begin{array}{l}\text { (13) Sadakata T, Shinoda Y, Oka M, } \\
\text { Sekine Y, Furuichi T. } 2013\end{array}$ & Camundongos $\mathrm{HE}^{* *}$ CAPS2. & Camundongos heterozigotos CAPS2. & $\begin{array}{l}\text { Teste de campo aberto, teste de reconhecimento } \\
\text { de objeto novo. }\end{array}$ \\
\hline
\end{tabular}


(15) Wang L, Almeida LEF, Spornick NA, Kenyon N, Kamimura $S$, Khaibullina A, Nouraie M, Quezado ZMN. 2016.

(17) Kane MJ, Angoa-Peréz M, Briggs DI, Sykes CE, Francescutti DM, Rosenberg DR, Kuhn DM. 2012.
Camundongos BTBR, n=3-5/gaiola.

Machos e fêmeas.

Camundongos BTBR e B6

Camundongos TPH2 foram derivados de cruzamentos de machos heterozigotos (TPH2 +/-) e fêmeas heterozigotas (Tph2 +/-) em um fundo C57BL/6-Sv129 misto.

Camundongos Shank3B e mutantes nulos foram gerados cruzando machos heterozigotos de 8 a 14 semanas de idade com fêmeas heterozigotas da mesma idade. consideração ao baixo do Shank3Bcolônia reprodutiva, todos os descendentes sobreviventes foram usados para testes.
Camundongos TPH2. As ninhadas foram separadas por sexo.
18) Dhamne SC, Silverman JL, Super CE, Lammers SHT, Hameed MQ, Mod DG, Rotenberg A, Crawley JN, Sahi M. 2017.
(19) Angoa-Pérez M, Kane MJ, Briggs DI, Francescutt DM, Kuhn DM. 2013.

(20) Du L, Zhao G, Duan Z, Li F. 2017.

(21) Silverman JL, Oliver CF, Karras MN, Gastrell PT, Crawley JN. 2013.

(22) Mehta MV, Gandal MJ, Siegel SJ. 2011.

(25) Schneider T, Roman A, BastaKaim A, Kubera M, Budziszewska B, Schneider K, Przewlocki R. 2008.

(26) Degroote S, Hunting D, Takser L. 2018.

(27) Morakotsriwan N, Wattanathorn J, Kirisattayakul W, Chaisowamongkol K. 2016.

(28) Moy SS, Nadler JJ, Young NB, Perez A, Holloway LP, Barbaro RP, Wilson LM, Threadgill DW, Lauder JM. Magnuson, T.R. 2007.

(34) Greco B, Managò F, Tucci V, Kao H, Valtorta F, Benfenati F. 2013.
Camundongos TPHSKO***

Ratos Wistar ( $n=4$ fêmeas) e seus filhotes ( $n=20$ machos)

Camundongos BTBR $T+t f / J$ (BTBR). Após o desmame, os juvenis foram alojados em gaiolas de três e quatro, por sexo linhagem.

Camundongos $\mathrm{C} 57 \mathrm{BL} / 6 \mathrm{Hsd}$ (B6). ( $n=10$ fêmeas) e seus filhotes (24=machos)

\section{Ratos Wistar. Os experimentos} foram realizados em filhos adulto do sexo masculino e feminino das fêmeas.

Ratos Wistar. ( $\mathrm{n}=12$ fêmeas) divididas em 2 grupos de 6 mães cada.
Camundongos sem o gene para triptofano hidroxilase 2 (TPH2).

Fase pré-natal: Agente indutor de TEA: VPA $(600 \mathrm{mg} / \mathrm{kg})$; Tempo: E12.5 dias.

Os camundongos BTBR T + tf/J (BTBR) foram alojados e criados usando trios de reprodução de harém.

Fase pré-natal: Agente indutor de TEA: VPA $(600 \mathrm{mg} / \mathrm{kg})$; Tempo: E13 dias.

Fase pré-natal: Agente indutor de TEA: VPA $(600 \mathrm{mg} / \mathrm{kg})$; Tempo: E12.5 dias.

Grupo controle: alimentadas com Dieta Basal 5755 (folato $4,2 \mathrm{mg} / \mathrm{kg}$; colina $1400 \mathrm{mg} / \mathrm{kg}$ ) de TestDiet ${ }^{\circledR}$ até G15; Grupo de indução chamado FD: déficit de folato peri-conceitual alimentado com Dieta 5BRC de TestDiet ${ }^{\circledR}$ até G15, que é semelhante à Dieta Basal 5755 em todos os nutrientes, exceto para ácido fólico $(0,2$ $\mathrm{mg} / \mathrm{kg}$ ) e colina $(750 \mathrm{mg} / \mathrm{kg})$, que é uma ingestão diária mínima para roedores, e a adição de SST 1\%.

Pós-natal: Agente indutor de TEA: VPA (400 mg/kg); Tempo: $14 \mathrm{~d}$.

Descendentes de machos e fêmeas, grupo.

\section{( $\mathrm{n}=20$ machos) de cepas} consanguíneas, $C 57 \mathrm{~B} / 6 \mathrm{~J}, \mathrm{C} 57 \mathrm{~L} / \mathrm{J}$, $\mathrm{DBA} / 2 \mathrm{~J}, \mathrm{FVB} / \mathrm{NJ}, \mathrm{AKR} / \mathrm{J}, \mathrm{A} / \mathrm{J}$, BALB/cByJ e 129S1/SvImJ, $(n=19$ machos) da cepa $\mathrm{C} 3 \mathrm{H} / \mathrm{HeJ}$, ( $\mathrm{n}=24$ machos) do BTBR T + tfA estirpe/J.

\section{Camundongos C57BL / $6 \mathrm{~J}$.}

Roedores machos de dois meses (jovens) e 6 meses (adultos) de ambos os genótipos foram usados para as experiências comportamentais.
Gerados SynI -/- , SynII -/- e SynIII -/ murganhos, foram retrocruzadas com um fundo $\mathrm{C} 57 \mathrm{BL} / 6 \mathrm{~J}$ através de, pelo menos, dez gerações.
Escolha de cheiro materno, teste de memória social, teste de objeto novo, discriminação olfativa social, interação social direta, teste de sociabilidade de três câmaras, marcação de cheiro de urina, trituração de ninho, enterramento de mármore, escavação compulsiva.

Interações sociais recíprocas juvenis, labirinto em cruz elevado, transições claro囚escuro, locomoção em campo aberto, reconhecimento de objetos novos, auto-limpeza repetitiva e sepultamento de mármore, abordagem social de três câmaras, habituação / desabituação olfativa, prato quente, interação social homemmulher, Condicionamento do medo, aquisição do labirinto de água de Morris.

Teste de enterramento de mármore, teste de fragmentação de Nestlet.

Teste de auto-limpeza, habituação / desabituação olfativa, interação social.

Abordagem social, teste de interação social masculino-feminino, Ensaio de auto-limpeza, Locomoção em campo aberto, Reconhecimento de objeto novo.

Ensaio de auto-limpeza, teste de campo aberto e locomotor, ensaio de enterramento de mármore.

Reatividade nociceptiva, atividade locomotor e repetitiva/estereotípica, labirinto em cruz elevado, comportamento social.

Campo aberto, interações sociais, enterro de mármore, labirinto em cruz elevado.

Teste da placa quente, interação social, teste do labirinto em cruz elevado, teste do labirinto aquático de Morris, teste do Rotarod, comportamentos de estereótipo.

Campo aberto, Sociabilidade e preferência pela novidade social, Teste olfativo, teste de comportamento social, Teste do labirinto em cruz elevado, Labirinto em T, Teste do labirinto de água.

Campo aberto, teste claro-escuro, teste de preferência de sociabilidade e novidade social, teste de reconhecimento social, teste de tubo para dominação social, teste de intrusoresidente, teste de transferência social de preferência alimentar, teste olfativo de comida enterrada, teste de enterrar mármore e autolimpeza comportamento. 
1. APA. (APA). Diagnostic and statistical manual of mental disorders. 5nd. American Psychiatric Association. 2013. 948p.

2. Brodkin, ES. BALB/c mice: low sociability and other phenotypes that may be relevant to autism. Behav Brain Res. 2007;176(1):53-65. DOI: 10.1016/j.bbr.2006.06.025

3. Wagner GC, Reuhl KR, Cheh M, Mcrae P, Halladay AKA. A new neurobehavioral model of autism in mice: pre-and postnatal exposure to sodium valproate. J Autism Dev Disord. 2006;36(6):779-793. DOI: 10.1007/s10803006-0117-y

4. Hirsch MM, Deckmann I, Fontes-Dutra M, Bauer-Negrini G, Nunes GDF, Nunes W, Rabelo B, Riesgo R, Margis R, Bambini-Junior V, Gottfried C. Behavioral alterations in autism model induced by valproic acid and translational analysis of circulating microRNA. Food Chem Toxicol. 2018; 115:336-343. DOI: 10.1016/j.fct.2018.02.061

5. Bambini-Junior V, Rodrigues L, Behr GA, Moreira JCF, Riesgo R, Gottfried C. Animal model of autism induced by prenatal exposure to valproate: behavioral changes and liver parameters. Brain Res. 2011;1408:8-16. DOI: 10.1016/j.brainres.2011.06.015

6. Hamilton SM, Spencer CM, Harrison WR, Yuva-Paylor LA, Graham DF, Daza RAM, Hevner RF, Overbeek PA, Paylor R. Multiple autism-like behaviors in a novel transgenic mouse model. Behav Brain Res. 2011; 218(1):29-41. DOI: 10.1016/j.bbr.2010.11.026

7. Schlickmann E, Fortunato JJ. O uso de ácido valproico para a indução de modelos animais de autismo: uma revisão. J Bras Psiquiatr. 2013; 62(2):151-159. DOI: 10.1590/S0047-20852013000200009

8. Chao OU, Yunger R, Yang Y. Behavioral assessments of BTBR T+ Itpr3tf/J mice by tests of object attention and elevated open platform: implications for an animal model of psychiatric comorbidity in autism. Behav Brain Res. 2018;347:140-147. DOI: 10.1016/j.bbr.2018.03.014

9. Cai Y, Wang L, Xiao R, Li X, He X, Gao J, Xu H, Fan X. Autism-like behavior in the BTBR mouse model of autism is improved by propofol. Neuropharmacol 2017; 118:175-187. DOI: 10.1016/j.neuropharm.2017.03.021

10. Matsui F, Hecht P, Yoshimoto K, Watanabe Y, Morimoto M, Fritsche K, Will W, Beversdorf D. DHA mitigates autistic behaviors accompanied by dopaminergic change in a gene/prenatal stress mouse model. Neuroscience. 2018;371:407-419. DOI: 10.1016/j.neuroscience.2017. 12.029

11. Wöhr M, Scattoni ML. Behavioural methods used in rodent models of autism spectrum disorders: current standards and new developments. Behav Brain Res. 2013;251:5-17. DOI: 10.1016/j.bbr.2013.05.047
12. Chang Y, Cole TB, Costa LG. Prenatal and early-life diesel exhaust exposure causes autism-like behavioral changes in mice. Part Fibre Toxicol. 2018;15(1):1-14. DOI: 10.1186/s12989-018-0254-4

13. Sadakata T, Shinoda Y, Oka M, Sekine Y, Furuichi T. Autistic-like behavioral phenotypes in a mouse model with copy number variation of the CAPS2/CADPS2 gene. FEBS letters. 2013;587(1):54-59. DOI: 10.1016/j. febslet.2012.10.047

14. Hall CS. Emotional behavior in the rat. I. Defecation and urination as measures of individual differences in emotionality. J Comp Psychol. 1934;18(3):385. DOI: 10.1037/h0071444

15. Wang L, Almeida LEF, Spornick NA, Kenyon N, Kamimura S, Khaibullina A, Nouraie M, Quezado ZMN. Modulation of social deficits and repetitive behaviors in a mouse model of autism: the role of the nicotinic cholinergic system. Psychopharmacol. 2015;232(23):4303-4316. DOI: 10.1007/s00213-0154058-z

16. Gabriels, RL, et al. Is there a relationship between restricted, repetitive, stereotyped behaviors and interests and abnormal sensory response in children with autism spectrum disorders?. Res Autism Spectr Disord. v. 2, n. 4, p. 660-670, 2008.

17. Kane MJ, Angoa-Peréz M, Briggs DI, Sykes CE, Francescutti DM, Rosenberg DR, Kuhn DM. Mice genetically depleted of brain serotonin display social impairments, communication deficits and repetitive behaviors: possible relevance to autism. PloS One. 2012;7(11):e48975. DOI: 10.1371/journal.pone.0048975

18. Dhamne SC, Silverman JL, Super CE, Lammers SHT, Hameed MQ, Modi ME, Copping NA, Pride MC, Smith DG, Rotenberg A, Crawley JN, Sahin M. Replicable in vivo physiological and behavioral phenotypes of the Shank3B null mutant mouse model of autism. Mol Autism. 2017;8(1):1-19. DOI: 10.1186/s13229-0170142-z

19. Angoa-Pérez M, Kane MJ, Briggs DI, Francescutt DM, Kuhn DM. Marble burying and nestlet shredding as tests of repetitive, compulsive-like behaviors in mice. J Vis Exp. 2013;82:e50978. DOI: 10.3791/50978

20. Du L, Zhao G, Duan Z, Li F. Behavioral improvements in a valproic acid rat model of autism following vitamin $D$ supplementation. Psychiatry Res. 2017;53:28-32. DOI: 10.1016/j.psychres.2017.03.003

21. Silverman JL, Oliver CF, Karras MN, Gastrell PT, Crawley JN. Ampakine enhancement of social interaction in the BTBR mouse model of autism. Neuropharmacology. 2013;64:268-282. DOI: 10.1016/j. neuropharm.2012.07.013 
22. Mehta MV, Gandal MJ, Siegel SJ. mGluR5-antagonist mediated reversal of elevated stereotyped, repetitive behaviors in the VPA model of autism. PloS One. 2011;6(10):e26077. DOI: 10.1371/journal.pone.0026077

23. Pellow S, File SE. Anxiolytic and anxiogenic drug effects on exploratory activity in an elevated plus-maze: a novel test of anxiety in the rat. Pharmacol Biochem Behav. 1986;24(3):525-529.

24. Morato S. O papel da visão na aversão aos espaços abertos no labirinto em cruz elevado. Psicologia USP. 2006;17(4):159-174. DOI: 10.1590/S0103-6564200600 0400009

25. Schneider T, Roman A, Basta-Kaim A, Kubera M, Budziszewska B, Schneider K, Przewlocki R. Genderspecific behavioral and immunological alterations in an animal model of autism induced by prenatal exposure to valproic acid. Psychoneuroendocrinol. 2008;33(6): 728-740. DOI: 10.1016/j.psyneuen.2008.02.011

26. Degroote S, Hunting D, Takser L. Periconceptional folate deficiency leads to autism-like traits in Wistar rat offspring. Neurotoxicol Teratol. 2018;66:132-138. DOI:10.1016/j.ntt.2017.12.008

27. Morakotsriwan N, Wattanathorn J, Kirisattayakul W, Chaisowamongkol K. Autistic-like behaviors, oxidative stress status, and histopathological changes in cerebellum of valproic acid rat model of autism are improved by the combined extract of purple rice and silkworm pupae. Oxid Med Cell Longev. 2016;2016. DOI: $10.1155 / 2016 / 3206561$
28. Moy SS, Nadler JJ, Young NB, Perez A, Holloway LP, Barbaro RP, Wilson LM, Threadgill DW, Lauder JM. Magnuson, T.R. Mouse behavioral tasks relevant to autism: phenotypes of 10 inbred strains. Behav Brain Res. 2007;176(1):4-20. DOI: 10.1016/j.bbr.2006.07.030

29. Nason, B. The Autism Discussion Page on anxiety, behavior, school, and parenting strategies: A toolbox for helping children with autism feel safe, accepted, and competent. Jessica Kingsley Publishers, 2014.

30. Chang Y, Cole TB, Costa LG. Behavioral phenotyping for autism spectrum disorders in mice. Curr Protoc Toxicol. 2017;72(1):11-22. DOI: 10.1002/cptx.19

31. Arrant AE, Schramm-Sapyta NL, Kuhn CM. Use of the light/dark test for anxiety in adult and adolescent male rats. Behav Brain Res. 2013;256:119-127. DOI: 10.1016/j.bbr.2013.05.035

32. Salari A, Amani M. Neonatal blockade of GABA-A receptors alters behavioral and physiological phenotypes in adult mice. Int J Dev Neurosci. 2017;57:62-71. DOI: 10.1016/j.ijdevneu.2017.01.007

33. Bourin M, Hascoët M. The mouse light/dark box test. Eur J Pharmacol. 2003;463(1-3):55-65. DOI: 10.1016/ S0014-2999(03)01274-3

34. Greco B, Managò F, Tucci V, Kao H, Valtorta F, Benfenati F. Autism-related behavioral abnormalities in synapsin knockout mice. Behav Brain Res. 2013;251:65-74. DOI: 10.1016/j.bbr.2012.12.015 